Research Article

\title{
Adaptive Capacity of the Communities in View of Climate Change in Areas Vulnerable to Malaria in the Himalayan Region of India
}

\author{
Syed Shah Areeb Hussain, Vijay P Ojha, Gaurav Kumar, Poonam Singh, Ramesh C Dhiman
}

ICMR - National Institute of Malaria Research, Sector 8, Dwarka, New Delhi, India.

DOI: https://doi.org/10.24321/0019.5138.202150

I $\quad \mathbf{N} \quad \mathbf{F} \quad \mathbf{O}$

\section{Corresponding Author:}

Ramesh C Dhiman, ICMR - National Institute of Malaria Research, Sector 8, Dwarka, New Delhi, India.

E-mail Id:

r.c.dhiman@gmail.com

Orcid Id:

https://orcid.org/0000-0001-9844-9970

How to cite this article:

Hussain SSA, Ojha VP, Kumar G, Singh P, Dhiman RC. Adaptive Capacity of the Communities in View of Climate Change in Areas Vulnerable to Malaria in the Himalayan Region of India. J Commun Dis. 2021;53(3):143-152.

Date of Submission: 2021-06-28

Date of Acceptance: 2021-08-20
$\begin{array}{lllllllll}\mathbf{A} & \mathbf{B} & \mathbf{S} & \mathbf{T} & \mathbf{R} & \mathbf{A} & \mathbf{C} & \mathbf{T}\end{array}$

Background: Malaria is one of the major public health problems in India and climate change is expected to aggravate the situation by opening new windows for transmission, particularlyin the Himalayan region. It is, therefore, essential to identify knowledge gapsand adaptive capacity of communities to the adverse impacts of climate change, to develop adaptation plan and improve resilience.

Methods: The adaptive capacity to potential risks of malaria due to climate change was assessed in the states of Himachal Pradesh and Uttarakhand, based on the knowledge, attitude, health seeking behaviour, practices and socio-economic status of the communities. The preparedness of health facilities was also assessed in the respective healthcare facilities in view of the threat of climate change.

Results: Though communities had basic knowledge about malaria, lack of specific knowledge about breeding sources of mosquitoes, use of traditional protective measures (41\%) from mosquito bites, delayed health seeking behaviour by $40 \%$ households (2-4 days after illness) were found unsatisfactory.The assessment of health system revealed inadequacies in capacity for beds at CHCs (in 60\%), lack of training of staff and logistics in preparedness for the threat of malaria.

Conclusion: The general knowledge of communities regarding malaria was satisfactory, but several misconceptions which may affect the vulnerability to future risk of malaria were found. The adaptive capacity was found slightly above average (57.04) owing to the overall good socio-economic status. However, lack of proper health care infrastructure may impact the overall adaptive capacity of the communities to malaria.

Keywords: Malaria, Climate Change, Knowledge, Adaptive Capacity, Himachal Pradesh

\section{Introduction}

Climate Change is an emerging public health problem which is affecting the distribution of malaria. ${ }^{1,2}$ Studies undertaken in India have projected the opening of new foci for malaria transmission in the Himalayan region by 2030s and altered windows of transmission in other parts ${ }^{2-4}$ as a result of climate change. The communities in the Himalayan 
region have little experience of malariaowing to very low endemicity due to low temperatures. In order to develop adaptation plan for vulnerable communities in Himalayan region, it is imperative to know the knowledge, attitude, health seeking behaviour, practices, and socio-economic status of the communities and the health system.

The societal response that enables the community to adapt and cope with adverse effects of climate change is defined as their adaptive capacity. Socio-economic status, knowledge and practices play a crucial role in building this resilience at the local level, which is supported by availability of adequate health infrastructure. ${ }^{5-7}$ The present study was, therefore, undertakenin vulnerable areas of the Himalayan region to assess the adaptive capacityof the communities as well as health system. The results of this study would guide the local health authorities to develop adaptation plan to combat the adverse impacts of climate change on malaria.

\section{Materials and Methods}

\section{Study Locations}

The study was conducted in districts Chamba and Kangra in Himachal Pradesh, and Tehri Garhwal and Almora in Uttarakhand, where 36 villages (Table 1) were selected from regions which are projected as vulnerable to malaria due to climate change. ${ }^{2,3}$ An assessment of the nearest primary and secondaryhealth centres was also conducted to ascertain their preparedness for potential risks of malaria and climate change based on the National Rural Health Mission (NRHM) norms. ${ }^{8}$

Table I.Details of Villages and Health Centres Surveyed

\begin{tabular}{|c|c|c|c|c|c|c|}
\hline District & $\begin{array}{l}\text { Date of } \\
\text { survey }\end{array}$ & Block & Village & $\begin{array}{c}\text { Total } \\
\text { population }\end{array}$ & $\begin{array}{l}\text { No. of } \\
\text { houses in } \\
\text { village }\end{array}$ & $\begin{array}{c}\text { No. of } \\
\text { houses } \\
\text { surveyed }\end{array}$ \\
\hline \multirow{7}{*}{$\begin{array}{l}\text { Tehri Garhwal } \\
\text { (Uttarakhand) }\end{array}$} & $10 / 01 / 2018$ & Devprayag & Bhadoli & 222 & 59 & 16 \\
\hline & \multirow{6}{*}{$12 / 01 / 2018$} & \multirow{6}{*}{ Devprayag } & Bagi & 93 & 27 & 6 \\
\hline & & & Gorti Kanda & 584 & 125 & 20 \\
\hline & & & Koti & 301 & 64 & 7 \\
\hline & & & Muneth & 408 & 97 & 20 \\
\hline & & & Rampur & 283 & 67 & 7 \\
\hline & & & Rampur-Shyampur & 452 & 109 & 10 \\
\hline \multirow{12}{*}{$\begin{array}{l}\text { Chamba } \\
\text { (Himachal } \\
\text { Pradesh) }\end{array}$} & \multirow{3}{*}{$30 / 01 / 2018$} & \multirow{3}{*}{ Samot } & Dentha & & & 12 \\
\hline & & & Samot & 817 & 184 & 3 \\
\hline & & & Har & & & 11 \\
\hline & \multirow{2}{*}{$31 / 01 / 2018$} & \multirow{2}{*}{ Pukhari } & Karori & 464 & 93 & 21 \\
\hline & & & Bhardawi & & & 9 \\
\hline & \multirow{3}{*}{$31 / 01 / 2018$} & \multirow{3}{*}{ Sundla } & Sundla & 464 & 91 & 15 \\
\hline & & & Danun & 515 & 103 & 16 \\
\hline & & & Koti & 55 & 17 & 16 \\
\hline & \multirow{4}{*}{$01 / 02 / 2018$} & \multirow{3}{*}{ Rajnagar } & Rajnagar & 1437 & 306 & 20 \\
\hline & & & Kiyani & 1539 & 319 & 18 \\
\hline & & & Ramgarah & & & 6 \\
\hline & & Kakira & Nainikhad & 416 & 93 & 12 \\
\hline \multirow{4}{*}{$\begin{array}{c}\text { Kangra } \\
\text { (Himachal } \\
\text { Pradesh) }\end{array}$} & \multirow{2}{*}{$30 / 01 / 2018$} & \multirow{2}{*}{ Tiara } & Lulehr & 1253 & 270 & 17 \\
\hline & & & Tarsuh & 821 & 161 & 15 \\
\hline & $31 / 01 / 2018$ & Jia & Jia & 212 & 52 & 7 \\
\hline & 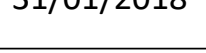 & Gopalpur & Gopalpur & 918 & 202 & 7 \\
\hline \multirow{5}{*}{$\begin{array}{c}\text { Almora } \\
\text { (Uttarakhand) }\end{array}$} & \multirow{5}{*}{$13 / 02 / 2018$} & \multirow{4}{*}{ Takula } & Amkholi & 259 & 67 & 11 \\
\hline & & & Bina & 134 & 24 & 15 \\
\hline & & & Chaupata & & & 14 \\
\hline & & & Kandey & 930 & 198 & 9 \\
\hline & & Baisiyachhina & Kalon & 416 & 116 & 13 \\
\hline
\end{tabular}




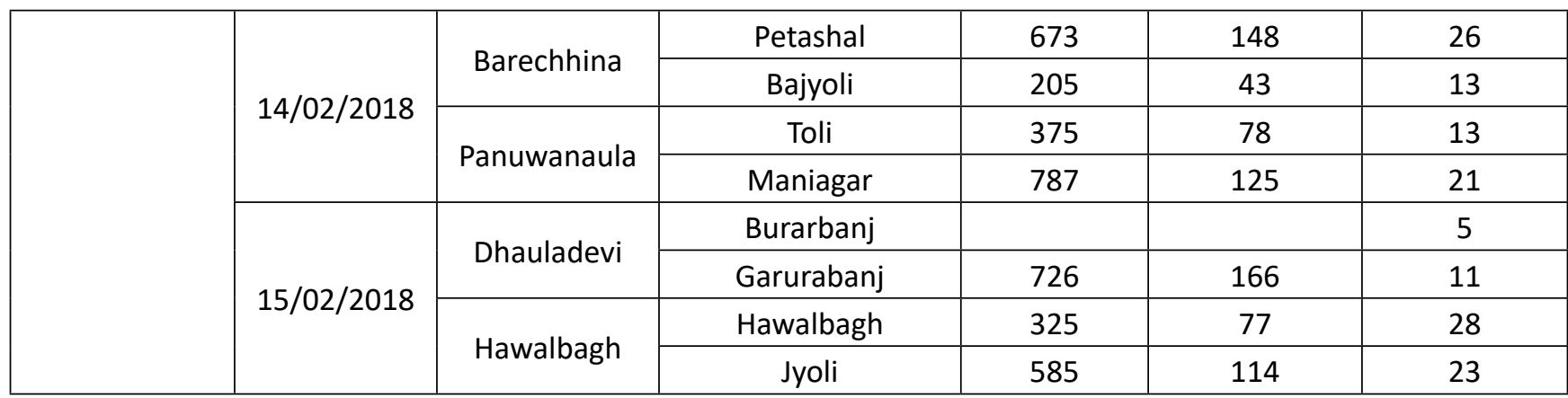

\section{Study Design}

Adaptive Capacity of communities for potential risk of malaria in selected districts was assessed with the help of a structured interview schedule based on knowledge of disease, attitudeand practices for vector control, health seeking behaviour and socio-economic status (KABPS). A separate set of interview schedulewas used to assess the preparedness of health systems based on knowledge of impacts of climate change on malaria and availability of adequate manpower and resources.

\section{Study Population and Participants}

Assuming a confidence level of $95 \%$ and margin of error $5 \%$, minimum sample size required to represent the population of $3,270,592$ in the selected districts was found to be 384 . Households were selected by random sampling (minimum $5 \%$ of households from each village) and in total, 493 households were interviewed.

\section{Data Collection and Analysis}

The data was collected in three field visits between 10-January to 15-February 2018. All the participants were informed about the purpose of the research and importance of their contribution. Informed consent was taken from each participant, with due regards to confidentiality. The interview schedule was then administered in 15-minute face to face interactionsand responses were noted on questionnaire sheets. The health system questionnaires were administered to the Medical Officers (MO) and the Block Malaria Officers (BMO) in the respective Health Centres.

To compute the KABPS score each response was scored either - 1 (incorrect/inappropriate responses), 0 ('Don't Know') or 1 (most appropriate response). Village and district wise adaptive capacities were evaluated by additive aggregation of KAPBS scores using equal weights, and converted to percentage. Cross tabulation, frequencies and Chi square testswere carried out using SPSS Software 17.0 to determine the dependenceof categorical variables. Multiple regression was used to analyse the association between continuous variables (KAPBS scores).

\section{Results}

\section{Demographic Characteristics}

The average size of the households was approximately 5 people per household, while the average age of respondents was 47 years. Male to female ratiowas approximately 7:3. Almost all respondents were indigenous (97.54).

\section{Socio-economic Status}

Most respondents (86.93\%) had someformal education of which $22 \%$ had studied up to high school while $23 \%$ were graduates or higher. Almost $23 \%$ of the respondents worked in the Private sector, $12 \%$ worked in the government sector, $18 \%$ were labourers and $19 \%$ were self-employed. Housewives constituted $19 \%$ of the respondent population while $9 \%$ were unemployed.

Table 2.Scores with Descriptive Statistics

\begin{tabular}{|c|c|c|c|c|c|c|c|}
\hline \multirow{2}{*}{ Variables } & \multicolumn{3}{|c|}{ Range } & \multirow{2}{*}{ Mean } & \multirow{2}{*}{$\begin{array}{c}25 \\
\text { percentile }\end{array}$} & \multirow{2}{*}{ Median } & \multirow{2}{*}{$\begin{array}{c}75 \% \\
\text { percentile }\end{array}$} \\
\hline & Low & Medium & High & & & & \\
\hline Literacy & 0 to 1 & 1.01 to 2 & 2.01 to 3 & 1.29 & 0 & 1 & 2 \\
\hline Socio-economic Status (S) & -5 to -1 & -1.01 to 3 & 3.01 to 7 & 3.47 & 2 & 4 & 5 \\
\hline Knowledge (K) & -10 to 0 & 0.01 to 9 & 9.01 to 18 & 8.89 & 5 & 8 & 10 \\
\hline Attitude (A) & 0 to 1 & 1.01 to 2 & 2.01 to 3 & 2.61 & 1 & 3 & 4 \\
\hline Practices $(\mathrm{P})$ & 0 to 3 & 3.01 to 6 & 6.01 to 9 & 3.61 & 3 & 4 & 4 \\
\hline Health seeking Behaviour (B) & -5 to 0 & 0 to 1.50 & 1.51 to 3 & 2.17 & 2 & 2 & 3 \\
\hline Total Adaptive Capacity (AC) & 0 to 33 & 33 to 66 & 66 to 100 & 63.10 & 57.25 & 65.17 & 71.69 \\
\hline
\end{tabular}


Though $43 \%$ of the respondents earned more than INR 100,000 annually, $12 \%$ were below poverty line (< INR 25,000 per annum).The number of mud houses was highest in Kangra (21.75\%) and lowest in Almora (3.05\%).

Most of the houses (89.87\%) had piped water supply. Hand pumps and streams were used less frequently (13.5\% and $24.68 \%)$.Domestic containers were the most common form of water storage $(61.03 \%)$ followed by overhead tanks $(48.82 \%)$. Cattle (cows and buffalos) were the most common type of livestock owned (1.22 per household), followed by goats and sheep (0.7 per household).

\section{Knowledge of Malaria and Climate Change}

Awareness of malaria was significantly high (92\%). Radio, television and newspapers were the most common source of information ( $86 \%$ ) followed by friends and family (26\%). Though role of mosquitoes in malaria transmission was well known (84\%), few respondents were aware of breeding sites, with many mistaking garbage as a breeding site (60\%).

The major symptom of malaria (high fever with chills) was fairly well known (69\%). While most respondents knew about anti-malarials (76\%), some were less familiar with malaria treatment (16\%).

Majority of the respondents were aware of climate change $(87 \%)$, believedit could affectmalaria (73\%) and had noticed significant changes in temperature and rainfall over the last 10 years (94\%). Cross tabulation results revealed that higher the literacy, greater the likelihood to understand the impact of climate change on malaria (Table 4).

\section{Attitude towards VBD Control}

More than half of the respondents considered malaria to be life threatening (59\%) and understood the role of both government intervention and personal protection in malaria control (55\%).

Table 3.Socio-economic and demographic characteristics of study population

\begin{tabular}{|c|c|c|c|c|c|}
\hline Attribute & Chamba & Kangra & Tehri Garhwal & Almora & Total \\
\hline Average size of family & 4.81 & 5.07 & 4.76 & 4.51 & 4.70 \\
\hline Average age of respondents (years) & 45.87 & 44.79 & 49.94 & 47.67 & 47.23 \\
\hline Gender & $\%$ & $\%$ & $\%$ & $\%$ & $\%$ \\
\hline Male & 65.81 & 67.50 & 79.07 & 69.70 & 68.56 \\
\hline Female & 36.77 & 47.50 & 20.93 & 29.80 & 31.44 \\
\hline No. of houses surveyed & 159.00 & 46.00 & 86.00 & 202.00 & 493.00 \\
\hline Education & $\%$ & $\%$ & $\%$ & $\%$ & $\%$ \\
\hline Illiterate (\%) & 9.77 & 14.63 & 16.88 & 12.96 & 12.83 \\
\hline Primary/Secondary School & 46.62 & 46.34 & 45.45 & 35.19 & 41.89 \\
\hline High School & 18.80 & 19.51 & 15.58 & 29.01 & 22.28 \\
\hline Graduate & 23.31 & 19.51 & 22.08 & 23.46 & 22.76 \\
\hline Occupation & $\%$ & $\%$ & $\%$ & $\%$ & $\%$ \\
\hline Labourer & 12.50 & 21.05 & 16.25 & 21.35 & 17.50 \\
\hline Government employee & 13.89 & 15.79 & 17.50 & 7.87 & 12.27 \\
\hline Private employee & 18.75 & 31.58 & 30.00 & 21.35 & 22.95 \\
\hline Housewife & 23.61 & 23.68 & 8.75 & 19.66 & 19.32 \\
\hline Self-employed & 20.14 & 7.89 & 22.50 & 18.54 & 18.86 \\
\hline Unemployed / Retired & 10.42 & 21.05 & 5.00 & 11.80 & 9.09 \\
\hline Annual income & $\%$ & $\%$ & $\%$ & $\%$ & $\%$ \\
\hline$<25,000$ & 4.17 & 13.95 & 21.79 & 13.89 & 11.98 \\
\hline $25,000-50,000$ & 4.86 & 23.26 & 12.82 & 30.56 & 17.36 \\
\hline $50,000-1,00,000$ & 28.47 & 11.63 & 25.64 & 32.64 & 27.63 \\
\hline$>1,00,000$ & 62.50 & 51.16 & 39.74 & 22.92 & 43.03 \\
\hline
\end{tabular}




\section{Behaviour and Practices}

Mosquito coils and traditional methods were the most common form of personal protection used $57 \%$ and $41 \%$ respectively), while bed nets and doors and window screens were rarely used ( $9 \%$ and $7 \%$ ). Use of personal protection was lowest in Tehri Garhwal (45\%). Almost all respondent kept water containers covered (97\%), and the majority cleaned containers at least once a week (81\%).

\section{Health Seeking Behaviour}

Almost all respondents (96\%) visited the nearest health facility in case of a recurrent or prolonged fever. There was very low preference for self-medication $(2.4 \%)$ and traditional healers or quacks (1.5\%). Government health centres were the most preferred health facility $(88.7 \%)$.
While more than half of the respondents sought treatment within the first 24 hours of fever (54\%), many waited at least 2 - 4 days before visiting a health facility (40\%). Lack of facilities (47.6\%) and medicines (31.5\%) were the most commonly cited reasons for preferring private over government health facilities. In most villages, regular health worker visits were not conducted (73.4\%).

\section{Adaptive Capacity of the Community}

The variable scores and total adaptive capacity was categorized into three groups (Table 5 ) - Low $\left({ }^{*}\right)$, Medium $\left({ }^{* *}\right)$ and High $\left({ }^{* * *}\right)$ based on the 25 th and 75 th percentiles. The overall adaptive capacity of both states was similar (57.89-Uttarakhand and 59.81-Himachal Pradesh). Almora had the highest adaptive capacity (61.10), while Tehri Garhwal had the lowest (50.45).

Table 4.KAPBS and Adaptive Capacity Scores of Different Villages

\begin{tabular}{|c|c|c|c|c|c|c|c|c|}
\hline District & PHC & Village & K & A & $\mathbf{P}$ & B & $\mathbf{S}$ & $\mathrm{AC}$ \\
\hline \multirow{7}{*}{$\begin{array}{l}\text { Tehri Garhwal } \\
\text { (Uttarakhand) }\end{array}$} & \multirow{7}{*}{ Devprayag } & Badhal & $7.19 * *$ & $1.50 * *$ & $3.50 * *$ & $2.63^{* * *}$ & $2.50 * *$ & $56.80 * *$ \\
\hline & & Bagi & $6.50 * *$ & $1.17 * *$ & $3.17 * *$ & $1.83 * * *$ & $1.17 * *$ & $50.06 * *$ \\
\hline & & Gorti Kanda & $4.89 * *$ & $1.04 *$ & $1.35^{*}$ & $1.00 * *$ & $2.40 * *$ & $46.93 * *$ \\
\hline & & Koti & $7.14 * *$ & $1.57 * *$ & $3.14 * *$ & $2.00 * * *$ & $6.14 * * *$ & $60.77 * *$ \\
\hline & & Muneth & $5.50 * *$ & $0.85 *$ & $2.90 *$ & $1.75 * * *$ & $3.20 * * *$ & $50.72 * *$ \\
\hline & & Rampur & $4.71 * *$ & $0.57^{*}$ & $1.71 *$ & $0.86 * *$ & $2.14^{* *}$ & $42.45 * *$ \\
\hline & & $\begin{array}{l}\text { Rampur- } \\
\text { Shyampur }\end{array}$ & $6.10 * *$ & $0.80 *$ & $3.50 * *$ & $1.90 * * *$ & $3.80 * * *$ & $53.63 * *$ \\
\hline \multicolumn{3}{|c|}{ District Average Score } & $5.66 * *$ & $1.01 *$ & $2.66^{*}$ & $1.71 * * *$ & $2.97^{* *}$ & $50.45 * *$ \\
\hline \multirow{12}{*}{$\begin{array}{l}\text { Chamba } \\
\text { (Himachal } \\
\text { Pradesh) }\end{array}$} & \multirow{3}{*}{ Samot } & Dentha & $7.33 * *$ & $1.42 * *$ & $3.83 * *$ & $2.00 * * *$ & $4.17 * * *$ & $58.52 * *$ \\
\hline & & Samot & $9.67 * * *$ & $2.00 * * *$ & $4.33 * *$ & $2.00 * * *$ & $5.00 * * *$ & $64.91 * * *$ \\
\hline & & Har & $8.91 * *$ & $2.18^{* * *}$ & $3.64 * *$ & $2.27 * * *$ & $4.64 * * *$ & $63.66 * * *$ \\
\hline & \multirow{2}{*}{ Pukhari } & Karori & $6.95 * *$ & $1.43 * *$ & $4.10 * *$ & $2.19 * * *$ & $3.48^{* * *}$ & $57.98^{* *}$ \\
\hline & & Bhardawi & $8.44 * *$ & $0.89 *$ & $4.00 * *$ & $2.00 * * *$ & $2.67 * *$ & $54.46 * *$ \\
\hline & \multirow{3}{*}{ Sundla } & Sundla & $6.8 * *$ & $2.27^{* * *}$ & $3.47 * *$ & $2.53 * * *$ & $5.40 * * *$ & $65.11 * *$ \\
\hline & & Danun & $7.31 * *$ & $1.81 * *$ & $3.50 * *$ & $2.56 * * *$ & $4.44 * * *$ & $61.20 * *$ \\
\hline & & Koti & $7.25 * *$ & $1.81 * *$ & $3.81 * *$ & $2.31 * * *$ & $5.06 * * *$ & $61.65^{* *}$ \\
\hline & \multirow{3}{*}{ Rajnagar } & Rajnagar & $6.00 * *$ & $1.60 * *$ & $3.35 * *$ & $2.45 * * *$ & $4.85 * * *$ & $59.55^{* *}$ \\
\hline & & Kiyani & $9.17^{* * *}$ & $2.06 * * *$ & $3.67 * *$ & $2.67^{* * *}$ & $5.56 * * *$ & $65.91 * * *$ \\
\hline & & Ramgarah & $9.50 * * *$ & $2.67 * * *$ & $3.50 * *$ & $2.17^{* * *}$ & $5.50 * * *$ & $66.86 * * *$ \\
\hline & Kakira & Nainikhad & $7.50 * *$ & $1.75 * *$ & $4.25 * *$ & $1.83 * * *$ & $4.83 * * *$ & $61.58 * * *$ \\
\hline \multicolumn{3}{|c|}{ District Average Score } & $7.57 * *$ & $1.70 * *$ & $3.74 * *$ & $2.26 * * *$ & $4.62 * * *$ & $61.02 * *$ \\
\hline \multirow{4}{*}{$\begin{array}{c}\text { Kangra } \\
\text { (Himachal } \\
\text { Pradesh) }\end{array}$} & \multirow{2}{*}{ Tiara } & Lulehr & $6.24 * *$ & $1.94 * *$ & $3.88 * *$ & $1.94 * * *$ & $3.88 * * *$ & $59.37 * *$ \\
\hline & & Tarsuh & $6.53 * *$ & $0.8^{*}$ & $3.13 * *$ & $1.80 * * *$ & $3.73 * * *$ & $52.74 * *$ \\
\hline & Jia & Jia & $4.86 * *$ & $1.14 * *$ & $2.86 *$ & $1.86 * * *$ & $2.00 * *$ & $49.63 * *$ \\
\hline & Gopalpur & Gopalpur & $7.57 * *$ & $1.71 * *$ & $3.57 * *$ & $1.86 * * *$ & $4.00 * * *$ & $58.65 * * *$ \\
\hline
\end{tabular}




\begin{tabular}{|c|c|c|c|c|c|c|c|c|}
\hline \multicolumn{3}{|c|}{ District Average score } & $6.33 * *$ & $1.41 * *$ & $3.43 * *$ & $1.87 * * *$ & $3.57 * * *$ & $55.60 * *$ \\
\hline \multirow{13}{*}{$\begin{array}{c}\text { Almora } \\
\text { (Uttarakhand) }\end{array}$} & \multirow{4}{*}{ Takula } & Amkholi & $\begin{array}{c}10.27 \\
* * *\end{array}$ & $2.27 * * *$ & $3.64 * *$ & $2.55 * * *$ & $3.46 * * *$ & $63.64 * * *$ \\
\hline & & Bina & $7.33 * *$ & $1.73 * *$ & $3.93 * *$ & $2.27 * * *$ & $2.93 * *$ & $58.62 * *$ \\
\hline & & Chaupata & $8.79 * * *$ & $2.00 * * *$ & $3.57 * *$ & $2.36 * * *$ & $2.71 * *$ & $59.71 * *$ \\
\hline & & Kandey & $8.00 * *$ & $2.44 * * *$ & $3.89 * *$ & $2.56 * * *$ & $1.22 * *$ & $59.68 * *$ \\
\hline & Baisiyachhina & Kalon & $8.08 * *$ & $1.92 * *$ & $3.54 * *$ & $2.31 * * *$ & $1.69 * *$ & $57.03 * *$ \\
\hline & \multirow{2}{*}{ Barechhina } & Petashal & $7.23 * *$ & $2.23 * * *$ & $4.04 * *$ & $2.04 * * *$ & $3.15 * * *$ & $60.57^{* * *}$ \\
\hline & & Bajyoli & $7.92 * *$ & $2.39 * * *$ & $4.15^{* *}$ & $2.31 * * *$ & $1.92 * *$ & $60.53 * * *$ \\
\hline & \multirow{2}{*}{ Panuwanaula } & Toli & $9.08 * * *$ & $2.15 * * *$ & $3.92 * *$ & $2.62 * * *$ & $2.54 * *$ & $61.65 * *$ \\
\hline & & Maniagar & $8.33 * *$ & $2.57 * * *$ & $4.29 * *$ & $2.14 * * *$ & $3.76 * * *$ & $64.49 * * *$ \\
\hline & \multirow{2}{*}{ Dhauladevi } & Burarbanj & $9.80 * * *$ & $2.60 * * *$ & $4.40 * *$ & $2.40 * * *$ & $3.40 * * *$ & $65.88 * * *$ \\
\hline & & Garurabanj & $8.36 * *$ & $2.18 * * *$ & $3.82 * *$ & $2.27 * * *$ & $1.27^{* *}$ & $58.09 * *$ \\
\hline & \multirow{2}{*}{ Hawalbagh } & Hawalbagh & $8.96 * * *$ & $2.39 * * *$ & $4.11 * *$ & $2.82 * * *$ & $3.54 * * *$ & $65.12 * * *$ \\
\hline & & Jyoli & $8.17^{* *}$ & $1.65 * *$ & $3.91 * *$ & $2.17 * * *$ & $2.48 * *$ & $57.82 * *$ \\
\hline \multicolumn{3}{|c|}{ District Average Score } & $8.35 * *$ & $2.17 * * *$ & $3.96 * *$ & $2.36 * * *$ & $2.77^{* *}$ & $61.10 * *$ \\
\hline
\end{tabular}

High*** | Medium $^{* *}$ | Low ${ }^{*}$.

Table 5.Correlation Matrix of Socio Demographic Factors and Outcome Scores

\begin{tabular}{|c|c|c|c|c|c|}
\hline & $\begin{array}{c}\text { Knowledge } \\
\text { score }\end{array}$ & $\begin{array}{c}\text { Attitude } \\
\text { score }\end{array}$ & $\begin{array}{c}\text { Practice } \\
\text { score }\end{array}$ & $\begin{array}{c}\text { Health seeking } \\
\text { behaviour }\end{array}$ & $\begin{array}{c}\text { Adaptive } \\
\text { capacity }\end{array}$ \\
\hline Age & 0.121 & -0.19 & -0.132 & -0.038 & -0.025 \\
\hline Family Size & -0.024 & -.117 & 0.065 & 0.003 & -0.052 \\
\hline Literacy & 0.278 & 0.207 & 0.091 & 0.104 & 0.282 \\
\hline Socio economic status & 0.213 & 0.239 & 0.219 & 0.194 & 0.534 \\
\hline Knowledge & - & 0.520 & 0.378 & 0.385 & 0.687 \\
\hline Attitude & - & - & 0.395 & 0.288 & 0.839 \\
\hline Practice & - & - & - & 0.435 & 0.652 \\
\hline Health Seeking Behaviour & - & - & - & 1.00 & 0.570 \\
\hline
\end{tabular}

Knowledge of malaria and climate change washighly correlated with attitude and health seeking behaviour and moderately correlated to behaviour and practices. Literacy was found to have weak association with KAPBS scores and adaptive capacity, while age and family size showed no significant correlation (Table 5).

\section{Health System Assessment}

On an average, $21 \%$ of the posts in the Health centres surveyed were vacant (Table 6 ). More than $33 \%$ of the $\mathrm{PHCs}$ and $60 \%$ of the $\mathrm{CHCs}$ lacked the required number of beds as per NRHM norms.

Spray pumps and insecticides were present in only $33.3 \%$ and $16.7 \%$ of the health centres surveyed, as the districts are not selected for Indoor Residual spraying due to low
API (<2). ${ }^{11}$ Rapid diagnostic kits for malaria were present in only $16.7 \%$ whereas anti-malarials were available in $41.7 \%$ of the health centres. Chloroquine and primaquine were the only anti-malarials available. More than $33 \%$ of the Health Centres lacked basic diagnostic equipment.

Most of the health professionals were aware about climate change and its effect on potential risk of malaria. However, more than $90 \%$ of the health professionals had no knowledge of the locally prevalent vectors.

\section{Discussion}

Knowledge, attitude and practice (KAP) surveys have been used previously and was used to assess the adaptive capacity of communities to potential risk of malaria due to climate change. ${ }^{9-12}$ 
Table 6.Preparedness of Health Systems in Vulnerable Areas of Malaria due to Climate Change

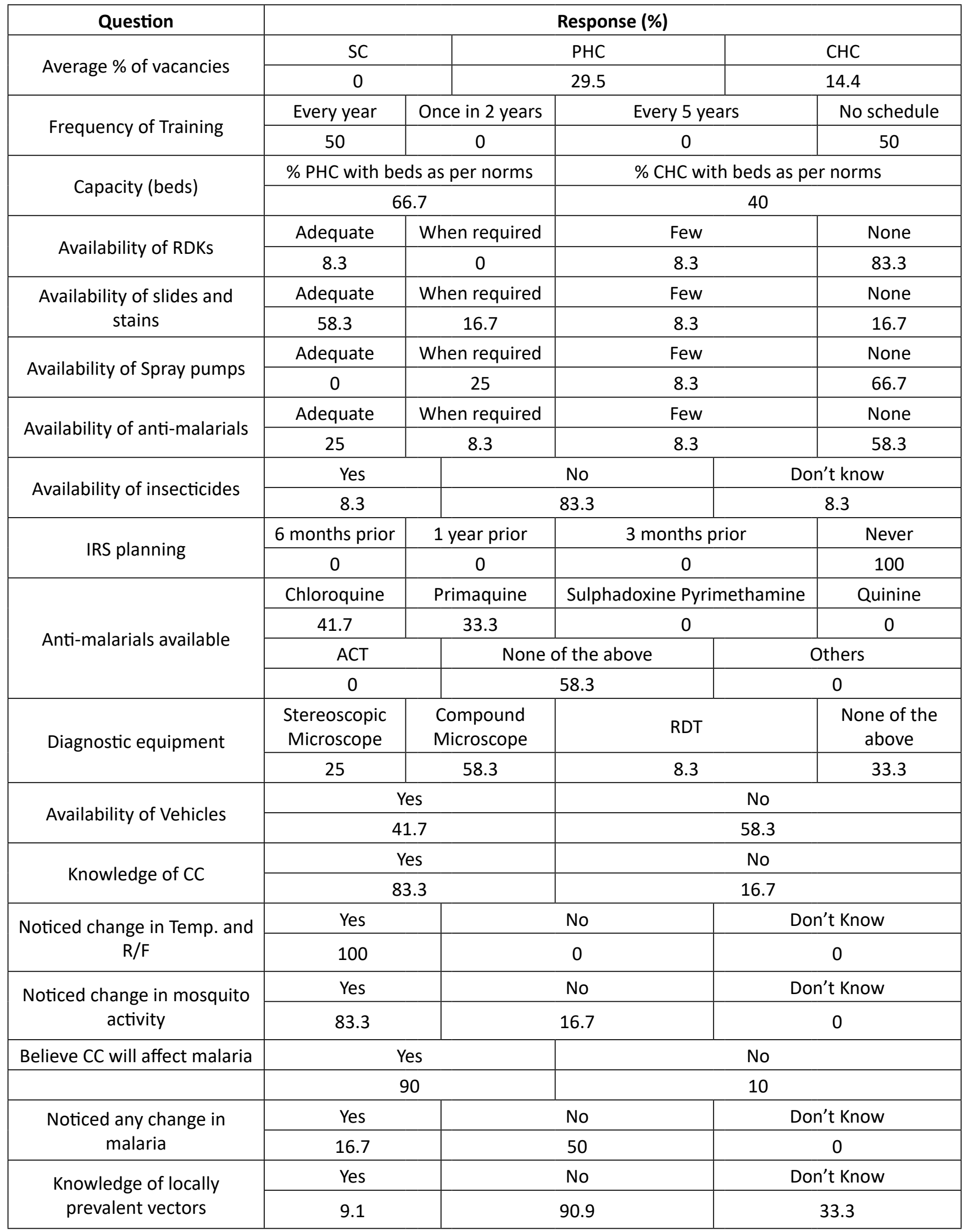




\begin{tabular}{|c|c|c|c|c|}
\hline \multirow{2}{*}{ Plan for surveillance } & Fortnightly & Monthly & Seasonally & When needed \\
\cline { 2 - 5 } & 16.7 & 0 & 25 & 66.7 \\
\hline \multirow{2}{*}{ Records of surveillance } & Yes & No & & \\
\cline { 2 - 5 } & 83.3 & 16.7 & & \\
\hline
\end{tabular}

The socio-economic status of the communities was good, with only $12 \%$ households below the poverty line and $43 \%$ earning more than INR 100,000 per annum. This was reflected in better housing conditions observed in most of the villages surveyed.

Most people wereaware of only the basic knowledge regarding malaria (92\%) as it is one of the oldest and well-known diseases in India. How ever significant misconceptions regarding breeding sites and vector control methods were observed, with garbage often cited (60\%) as one of the main breeding sites for mosquitoes. The communities were also less aware about the symptoms of malaria (69\%) and its treatment methods (74\%). A quarter of the respondents were unaware about symptoms of malaria and several even attributed headaches and body aches as symptoms of malaria.

Television, radio and newspapers were the most commonly cited sources of information (80\%) followed by sharing of knowledge from family members living in cities (24\%). Earlier studies have highlighted the role of these factors in disseminating information regarding malaria. ${ }^{13-19}$ However, role of health professionals as source of information was slightly lower (21\%) than friends and family, which highlights the need for doctors and paramedical staff to take more active participation in information exchange. ${ }^{19,20}$ The impact of climate change was fairly well known and the majority of the respondents had noticed a significant change in climate and understood its impact.

No significant correlation was found between literacy and knowledge score in our study (Table 6). However, more than $70 \%$ of the respondents who were graduates or higher, had a high knowledge score as opposed to only $19 \%$ of the respondents who were illiterate. While some earlier studies have found that knowledge of VBD depends on literacy, ${ }^{15,21}$ some have also found no relation between the two. ${ }^{22}$ This shows that the majority of the population has basic awareness about malaria irrespective of education, whereas literacy plays a role in more specific knowledge. Knowledge of malaria was found to have a significant influence on the attitude and the HSB of the community.

The use of personal protective measures (PPM) for prevention from mosquito bites has been found to vary depending on the location. ${ }^{23-25}$ In the present study, use of PPM (mainly mosquito coils and traditional methods) was significantly high (41-57\%) in all the districts surveyed, indicating abundance of mosquitoes.The most common forms of PPM used were mosquito repellents followed by traditional methods such as burning certain plants or aromatic wood were. The usage of bed nets (9\%) was low as districts were non-endemic.

HSB of the community was generally high, as many of the villages surveyed were situated closeto a Health Centre. This could also be the reason for government health facilities being mostly preferred. More than $20 \%$ of the respondents in Tehri Garhwal were below the poverty line (annual income < INR 25,000) and $16.89 \%$ had no education, highest among the four districts. These factors, resulted in a lower knowledge score as well as a lower health seeking behaviour in the community when compared to the other districts.

In Uttarakhand, district Tehri Garhwal had a lower adaptive capacity (50.54), whereas Almora had higher adaptive capacity (61.1). In Himachal Pradesh, Chamba had high adaptive capacity (61.02), while Kangra had lower adaptive capacity (55.6). Villages Kiyani and Ramagarh in Chamba had the highest adaptive capacity, 65.91 and 66.86 respectively. On the other hand, villages Rampur and Gorti Kanda in Tehri Garhwal were found to be the most vulnerable with adaptive capacity 42.45 and 46.9 respectively.

The health system preparedness with respect to malaria was found grossly insufficient. A large number of the health centres did not have anti-malarials and lacked sufficient facilities for malaria diagnosis and treatment, as the area is non-endemic for malaria. A high percentage of vacancies in local health facilities also hampers their ability to cope with the potential risks of malaria.

The study suggests that the adaptive capacity of communities has scope of further improvement by providing specific health education about breeding habitats of mosquitoes, prevention from mosquito bites, signs and symptoms of malaria, importance of insecticidal spray and complete treatment. It was also observed that vector populations already exist in these districts and the emergence of malaria may have severe impacts on the community. It is, therefore, recommended to impart specific health education to communities about prevention from mosquito bites and strengthen health systems in terms of logistics and training of health officials so as to reduce the imminent impact of malaria in view of climate change.

\section{Conclusion}

The adaptive capacity of the communities in regions vulnerable to climate change and its potential impact 
on malaria, was assessed using a KABPS survey. It was found that awareness of malaria was limited to the basic knowledge ofmalaria, whereas knowledge regarding breeding sites, symptoms and treatment was lacking in the community. This resulted in poor practices in the community thatcould increase their exposure to mosquitoes, which were abundant in the surveyed villages. The health seeking behaviour of the community was satisfactory (96\%) as most respondents depended on the local health centres for treatment rather than quacks. However, the significant lack of preparedness was found (plan for training (50\%), microscope (33.3\%) and inadequate anti-malarials) in several health centres that were surveyed. Adaptive Capacity in District Almora was found best (61.1), while lowest (50.45) in Tehri Garhwal, which was basically due to difference in components of KABPS.

Significant efforts must be made to educate the communities about transmission and preventive measures of malaria and improve the health infrastructure by training of health personnel, procuring the necessary diagnostic equipment and medicine for detection and treatment of malaria to minimize the impacts of climate change on malaria in India.

\section{Declarations}

\section{Sources of Funding}

Funding for the research was obtained from the Ministry of Environment Forest and Climate Change, Government of India. The funding body approved the project for the study but played no role in collection, analysis and interpretation of data or in writing the manuscript.

\section{Acknowledgements}

We express our thanks to Ministry of Environment, Forest and Climate Change for financial support and to Director, National Institute of Malaria Research, Delhi for facilities. We also thank all the respondents who voluntarily participated in the study.

\section{List of Abbreviations}

AC: Adaptive Capacity

BCC: Behavioural Change Communication

BMO: Block Malaria Officer

CHC: Community Health Centre

IEC: Information, Education and Communication

KAPBS: Knowledge, Attitude, Practices, Health-Seeking

Behaviour and Socio-economic Status

KAP: Knowledge, Attitude and Practices

MO: Medical Officer

PHC: Primary Health Centre

PPM: Personal Protective Measures

RDK: Rapid Diagnostic Kits

SC: Sub-Centre

SAD: State Allopathic Dispensary
VBD: Vector Borne Diseases

\section{Conflict of Interest: None}

\section{References}

1. Dhiman RC, Pahwa S, Dhillon GPS, Dash AP. Climate change and threat of vector-borne diseases in India: Are we prepared? Parasitol Res. 2010 Mar;106(4):76373. [PubMed] [Google Scholar]

2. Dhiman RC, Chavan L, Pant M, Pahwa S. National and regional impacts of climate change on malaria by 2030. Curr Sci. 2011;101:372-83. [Google Scholar]

3. Sarkar S, Gangare V, Singh P, Dhiman RC. Shift in potential malaria transmission areas in India, using the fuzzy-based climate suitability malaria transmission (FCSMT) model under changing climatic conditions. Int J Environ Res Public Health. 2019 Sep;16(18):3474. [PubMed] [Google Scholar]

4. Dhiman $C$, Singh P, Yadav Y, Saraswat S, Kumar G, Singh R, Ojha VP, Joshi BC, Singh P. Preparedness for malaria elimination in the wake of climate change in the State of Uttarakhand (India). J Vector Borne Dis. 2019 JanMar;56:46-52. [PubMed] [Google Scholar]

5. IPCC, 2014: Climate Change 2014: Synthesis Report. Contribution of Working Groups I, II and III to the Fifth Assessment Report of the Intergovernmental Panel on Climate Change [Core Writing Team, R.K. Pachauri and L.A. Meyer (eds.)]. IPCC, Geneva, Switzerland, 151 pp.

6. Onyango EA, Sahin O, Awiti A, Chu C, Mackey B. An integrated risk and vulnerability assessment framework for climate change and malaria transmission in East Africa. Malar J. 2016 Nov;15(1):551. [PubMed] [Google Scholar]

7. Sutherst RW. Global change and human vulnerability to vector-borne diseases. Clin Microbiol Rev. 2004 Jan;17(1):136-73. [PubMed] [Google Scholar]

8. Indian Public Health Standard (IPHS): Guidelines for SubCentres. 2012. Directorate General of Health Services, Ministry of Health \& Family Welfare, Government of India.

9. Salim SS, Narayanakumar R, Remya R, Safeena PK, Rahman MR, James HE. Climate change impacts on livelihood vulnerability assessment-adaptation and mitigation options in marine hot spots in Kerala, India. Int J Environ Clim Chang. 2018;8:180-99. [Google Scholar]

10. Pandey R, Jha SK. Climate vulnerability index - measure of climate change vulnerability to communities: A case of rural Lower Himalaya, India. Mitig Adapt Strateg Glob Chang. 2012;17:487-506. [PubMed] [Google Scholar]

11. Hahn MB, Riederer AM, Foster SO. The Livelihood Vulnerability Index: A pragmatic approach to assessing risks from climate variability and change-A case study in Mozambique. Glob Environ Chang. 2009;19(1):74- 


\section{8. [Google Scholar]}

12. Gupta RK, Raina SK, Shora TN, Jan R, Sharma R, Hussain $S$. A household survey to assess community knowledge, attitude and practices on malaria in a rural population of Northern India. J Fam Med Prim Care. 2016 JanMar;5:101-7. [PubMed] [Google Scholar]

13. Sharma RK, Singh MP, Saha KB, Bharti PK, Jain V, Singh $\mathrm{PP}$, et al. Socio-economic and household risk factors of malaria in tribal areas of Madhya Pradesh, central India. Indian J Med Res. 2015 May;141:567-75. [PubMed] [Google Scholar]

14. Tyagi P, Roy A, Malhotra MS. Knowledge, awareness and practices towards malaria in communities of rural, semi-rural and bordering areas of east Delhi (India). J Vector Borne Dis. 2005 Mar;42(1):30-5. [PubMed] [Google Scholar]

15. Dhawan G, Joseph N, Pekow PS, Rogers CA, Poudel KC, Bulzacchelli MT. Malaria-related knowledge and prevention practices in four neighbourhoods in and around Mumbai, India: a cross-sectional study. Malar J. 2014 Aug;13:303. [PubMed] [Google Scholar]

16. Singh RK, Haq S, Dhiman RC. Studies on knowledge, attitude and practices in malaria endemic tribal areas of Bihar and Jharkhand, India. J Trop Dis. 2013;1. [Google Scholar]

17. Kumar BA, Madhavi. KVP. Knowledge and practice regarding vector borne diseases among slum dwellers of Guntur district, Andhra Pradesh. J Evol Med Dent Sci. 2013;2:4756-62.

18. Patel AB, Rathod H, Shah P, Patel V, Garsondiya J, Sharma R. Perceptions regarding Mosquito borne diseases in an urban area of Rajkot City. Natl J Med Res. 2011;1:2249-4995. [Google Scholar]

19. Anand T, Kumar R, Saini V, Meena G, Ingle G. Knowledge and use of personal protective measures against mosquito borne diseases in a resettlement colony of Delhi. Ann Med Health Sci Res. 2014 Mar;4:227-32. [PubMed] [Google Scholar]

20. Pandit N, Patel Y, Bhavsar B. Awareness and practice about preventive method against mosquito bite in Gujarat. Healthline. 2010;1:16-20. [Google Scholar]

21. Sharma AK, Bhasin S, Chaturvedi S. Predictors of knowledge about malaria in India. J Vector Borne Dis. 2007 Sep;44:189-97. [PubMed] [Google Scholar]

22. Alobuia WM, Missikpode C, Aung M, Jolly PE. Knowledge, Attitude, and Practices Regarding Vectorborne Diseases in Western Jamaica. Ann Glob Health. 2015 Sep-Oct;81(5):654-63. [PubMed] [Google Scholar]

23. Snehalatha KS, Ramaiah KD, Vijay Kumar KN, Das PK. The mosquito problem and type and costs of personal protection measures used in rural and urban communities in Pondicherry region, South India. Acta Trop. 2003 Sep;88(1):3-9. [PubMed] [Google Scholar]
24. Sharma SK, Jalees S, Kumar K, Rahman SJ. Knowledge, attitude and beliefs about malaria in a tribal area of Bastar district (Madhya Pradesh). Indian J Public Health. 1993 Oct-Dec;37:129-32. [PubMed] [Google Scholar]

25. Babu BV, Mishra S, Mishra S, Swain BK. Personalprotection measures against mosquitoes: a study of practices and costs in a district, in the Indian state of Orissa, where malaria and lymphatic filariasis are coendemic. Ann Trop Med Parasitol. 2007 Oct;101(7):6019. [PubMed] [Google Scholar] 